\title{
Design of the VISTA-ITL Test Facility for an Integral Type Reactor of SMART and a Post-Test Simulation of a SBLOCA Test
}

\author{
Hyun-Sik Park, Byung-Yeon Min, Youn-Gyu Jung, Yong-Cheol Shin, \\ Yung-Joo Ko, and Sung-Jae Yi \\ Thermal Hydraulics Safety Research Division, Korea Atomic Energy Research Institute, 989-111 Daedeokdaero, \\ Yuseong, Daejeon 305-353, Republic of Korea \\ Correspondence should be addressed to Hyun-Sik Park; hspark@kaeri.re.kr
}

Received 11 October 2013; Revised 25 February 2014; Accepted 22 May 2014; Published 26 June 2014

Academic Editor: Annalisa Manera

Copyright (C) 2014 Hyun-Sik Park et al. This is an open access article distributed under the Creative Commons Attribution License, which permits unrestricted use, distribution, and reproduction in any medium, provided the original work is properly cited.

\begin{abstract}
To validate the performance and safety of an integral type reactor of SMART, a thermal-hydraulic integral effect test facility, VISTAITL, is introduced with a discussion of its scientific design characteristics. The VISTA-ITL was used extensively to assess the safety and performance of the SMART design, especially for its passive safety system such as a passive residual heat removal system, and to validate various thermal-hydraulic analysis codes. The VISTA-ITL program includes several tests on the SBLOCA, CLOF, and PRHRS performances to support a verification of the SMART design and contribute to the SMART design licensing by providing proper test data for validating the system analysis codes. A typical scenario of SBLOCA was analyzed using the MARS-KS code to assess the thermal-hydraulic similarity between the SMART design and the VISTA-ITL facility, and a posttest simulation on a SBLOCA test for the shutdown cooling system line break has been performed with the MARS-KS code to assess its simulation capability for the SBLOCA scenario of the SMART design. The SBLOCA scenario in the SMART design was well reproduced using the VISTA-ITL facility, and the measured thermal-hydraulic data were properly simulated with the MARS-KS code.
\end{abstract}

\section{Introduction}

An integral effect test (IET) program was conducted by the Korea Atomic Energy Research Institute (KAERI) using the VISTA (experimental verification by integral simulation of transients and accidents) integral test loop (VISTA-ITL). The VISTA-ITL is a modified version of an existing VISTA facility [1] that has been modified to have the capability to simulate a small-break loss of coolant accident (SBLOCA) for the SMART (system-integrated modular advanced reactor) design [2]. The VISTA-ITL was used extensively to improve the safety and performance of the SMART design and to validate various thermal-hydraulic analysis codes such as the TASS/SMR-S [3] and MARS-KS [4].

The reference plant of the VISTA-ITL is a $330 \mathrm{MW}$ (thermal) class integral type reactor, SMART [2], which was developed by KAERI and licensed by the Korean regulatory body, nuclear safety, and security commission (NSSC) in June 2012. The SMART reactor is characterized by the introduction of simplified and improved safety systems such as the passive residual heat removal system (PRHRS) and its integral arrangement of the reactor vessel assembly, which makes it possible to remove the large pipe connections between the major components. It excludes the occurrence of a large break loss of coolant accidents (LBLOCA), but an SBLOCA is still a major concern for a safety analysis.

The VISTA-ITL is a reduced-height integral effect test facility based on the design features of SMART. The VISTAITL is used to investigate various thermal-hydraulic phenomena during the SBLOCA. The break flow rate, safety injection flow rate, and thermal-hydraulic behaviors of the major components for a typical break size and break locations are measured. The acquired data were used to validate the related thermal-hydraulic models of the safety analysis code, TASS/SMR-S [3], which can assess the capability of SMART to cope with the SBLOCA scenario. As the VISTAITL is capable of simulating various transient and accident conditions for the SMART design, it will greatly contribute to the enhancement of the SMART reactor's safety and performance. Recently, an experimental investigation of the SBLOCA scenario was also performed with a scaled integral test facility for a mall-sized integral PWR of REX-10 [5], and 
a thermal-hydraulic system code of TAPINS was developed to confirm the design decisions and analyze the transient responses of integral PWRs such as REX-10 [6].

Several tests were conducted using the VISTA-ITL facility in support of SMART standard design approval (SDA) and technology validation from 2009 through 2011 [7]. This paper presents an overview of the VISTA-ITL test program for the SMART design. The main focus is on the scientific design characteristics of the VISTA-ITL, its ability to simulate an SBLOCA scenario of the SMART design, and a brief introduction on the tests conducted. A pretest analysis of an SBLOCA was also performed to quantify the effects of possible scaling distortion and to assess the similarity between the VISTA-ITL and the SMART design. In addition, a posttest analysis of an SBLOCA test was performed to understand the general behavior of the VISTA-ITL and to assess the MARSKS models to simulate the VISTA-ITL test data.

\section{Scientific Design of the VISTA-ITL}

2.1. Existing VISTA Facility. The existing VISTA facility [2] is an integral effect test facility to simulate the primary and secondary systems as well as the major safety-related systems of the SMART-P. The reactor core is simulated by electric heaters with a capacity of $818.75 \mathrm{~kW}$, which is about $120 \%$ of the scaled full power. The scaled full power is $682.29 \mathrm{~kW}$. Unlike the integrated arrangements of the SMART-P, the VISTA primary components including a reactor vessel, a main coolant pump (MCP), a steam generator, and three pressurizers are connected to each other by pipes to facilitate the easy installation of the instrumentation and simple maintenance. The secondary system with a single train of a feed water supply tank (FWST), feed water line, steam generator (SG) secondary side, and steam line was simply designed to remove the primary heat source. A single train of the PRHRS is also installed. In addition to these major systems, a make-up water system and a feed water system are installed to control the feed water supply and its temperature.

The VISTA facility was designed to operate with a combination of manual and automatic operations. The controlled components include an electrical heating rod, a main coolant pump, a feed water control valve, a steam pressure control valve, an FWST heater, and a make-up pump. All safety-related accidents should be initiated and controlled by automatic control logics as they require automatic reactor trip logics to initiate the PRHRS. The corresponding trip logics, tables, and set points are programmed to control the sequence of events.

A set of experiments was performed for the SMART-P using the existing VISTA facility, which includes parametric studies on the thermal-hydraulic characteristics of the transient operation of an integral reactor [8] and experiments on the performance sensitivity of the passive residual heat removal system of an advanced integral type reactor [9].

2.2. Design Concept and Scaling Methodology of VISTA-ITL. In formulating the design concept, we had to consider the existing VISTA facility, which had been operated to simulate the SMART-P design. In the VISTA facility, the available core
TABLE 1: Major scaling parameters and ratios of the VISTA-ITL.

\begin{tabular}{lcc}
\hline Parameters & Scale ratio & Value \\
\hline Length, $l_{0 \mathrm{R}}$ & $l_{0 \mathrm{R}}$ & $1 / 2.77$ \\
Diameter, $d_{0 \mathrm{R}}$ & $d_{0 \mathrm{R}}$ & $1 / 21.746$ \\
Area, $a_{0 \mathrm{R}}$ & $d_{0 \mathrm{R}}^{2}$ & $1 / 472.9$ \\
Volume, $V_{0 \mathrm{R}}$ & $d_{0 \mathrm{R}}^{2} \cdot l_{0 \mathrm{R}}$ & $1 / 1310$ \\
Time scale & $l_{0 \mathrm{R}}^{1 / 2}$ & $1 / 1.664$ \\
Velocity & $l_{0 \mathrm{R}}^{1 / 2}$ & $1 / 1.664$ \\
Power/volume & $l_{0 \mathrm{R}}^{-1 / 2}$ & 1.664 \\
Heat flux & $l_{0 \mathrm{R}}^{-1 / 2}$ & 1.664 \\
Core power & $a_{0 \mathrm{R}} \cdot l_{\mathrm{OR}}^{1 / 2}$ & $1 / 787$ \\
Flow rate & $a_{0 \mathrm{R}} \cdot l_{\mathrm{OR}}^{1 / 2}$ & $1 / 787$ \\
Pump head & $l_{0 \mathrm{R}}$ & $1 / 2.77$ \\
Pressure drop & $l_{0 \mathrm{R}}$ & $1 / 2.77$ \\
\hline
\end{tabular}

heater power is $818.75 \mathrm{~kW}$ and the flow rates of the primary and secondary loops are 3.54 and $0.25 \mathrm{~kg} / \mathrm{s}$, respectively. Therefore, the VISTA facility was proven to have sufficient electrical and pumping capacities to simulate the operating conditions of the SMART design. The existing VISTA facility [2] was modified to have the simulation capability of an SBLOCA by installing a steam pressurizer, a safety injection system, a break simulation system, and so forth.

Finally, we chose the 1/2.77 height and 1/1310 volume-scale design for SMART, as summarized in Table 1. The reference scale ratios of the length and area are based on the elevation difference between the core and steam generator centers $(1 / 2.77)$ and the core flow area (1/472.9), respectively. Table 1 shows the major scaling parameters of the VISTA-ITL and its scaling ratios. The rationale for adopting the reduced-height design is similar to that for the ATLAS design [10]. As there is no absolute superiority between full-height and reducedheight designs, a decision could be made by considering the test objectives, prototype design characteristics, budget, and so forth. In the VISTA-ITL facility, the main reason for the adoption of the reduced-height design is to use the existing VISTA facility, which has a reduced-height geometry compared with the SMART design, and it was proven through various scoping analyses using best-estimate safety analysis codes that the VISTA-ITL facility can properly simulate the major sequence of events expected to occur in the SMART design. As the scale ratio of length is $1 / 2.77$, the time for the VISTA-ITL is 1.664 times faster than that for the SMART design. The scale ratios of both the core power and the flow rate are $1 / 787$, and the scale ratio of the pressure drop is $1 / 2.77$.

2.3. Scientific Design of the Systems and Components. The VISTA-ITL has been designed following the three-level scaling methodology of Ishii and Kataoka [11], which consists of integral scaling, boundary flow scaling, and local phenomena scaling. Figure 1 shows a schematic diagram of the VISTAITL facility. The major components of the reactor pressure vessel, steam generator, PRHRS, and secondary system are 


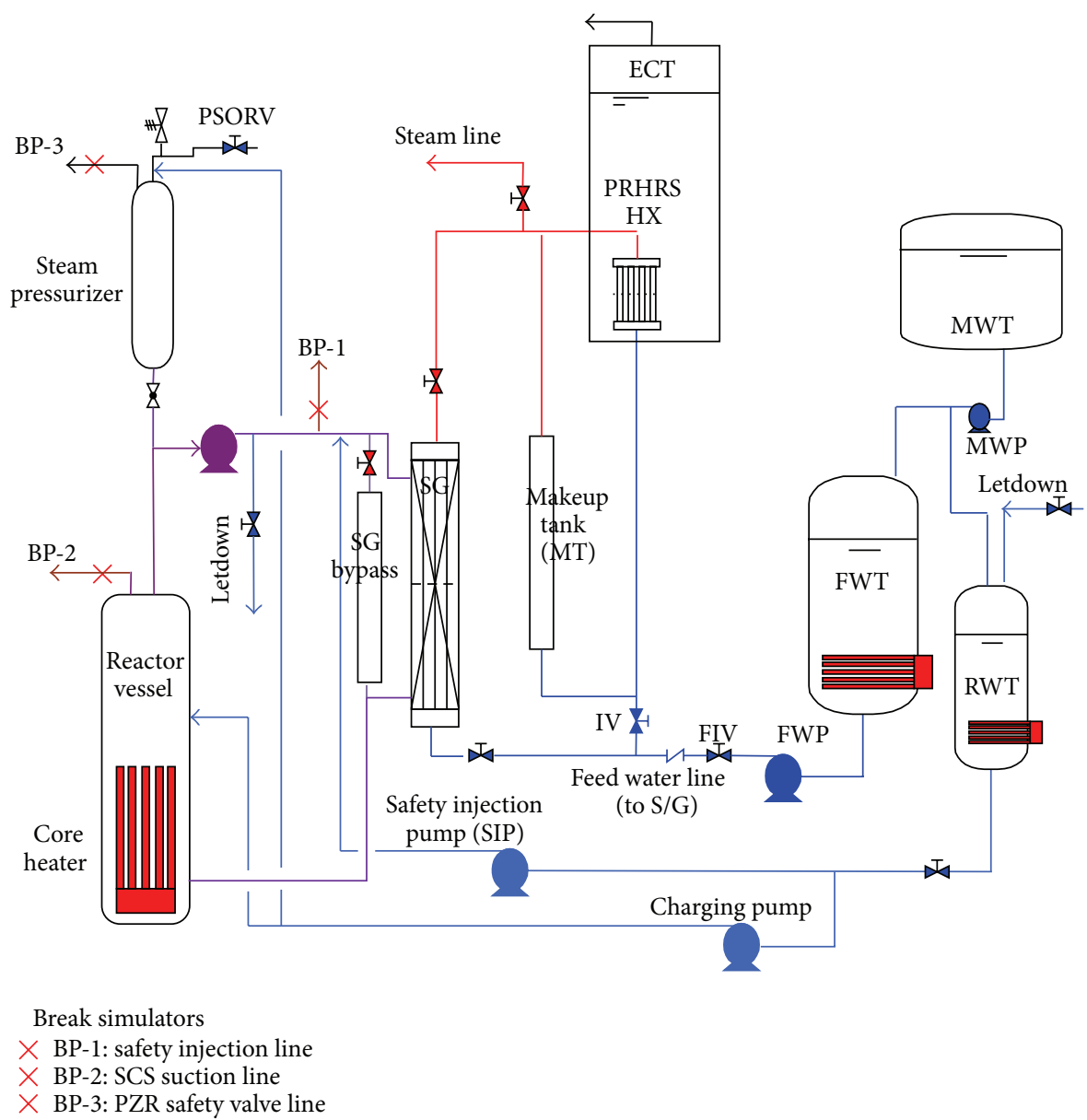

FIgURE 1: Schematic diagram of the VISTA-ITL facility.

preserved, which were described by Yi et al. [1], but some changes were made to simulate the SBLOCA behavior of the SMART design. They include a steam pressurizer, safety injection system, steam generator bypass, hot leg, cold leg, PRHRS makeup tank, break simulator, and break measuring system. These were designed to match the scaling ratios given in Table 1.

RPV and Core Heater. The primary loop of the VISTA-ITL facility is a single loop and is composed of a reactor pressure vessel (RPV) with a core heater, a main coolant pump (MCP), a steam generator (SG), and an interconnecting hot leg and a down-comer. In the VISTA-ITL facility, the core heater and MCP were proven to have sufficient electrical and pumping capacities to simulate the scaled full power and flow rate conditions of the SMART design, respectively. The SG bypass volume is added using a separate vessel to simulate the design characteristics of the SMART reactor. In addition, the volumes of the pump discharge line (so-called hot leg) and SG outlet region (so-called cold leg) are expanded to have scaleddown values of SMART.

Steam Pressurizer. The steam pressurizer is installed instead of the self-pressurized pressurizer of the existing VISTA facility.
The steam pressurizer of the SMART design was scaleddown following the scaling ratios in Table 1, and its bottom is connected to the upper part of the RPV before the RCP suction.

Steam Generator. The steam generator is composed of 12 helically coiled tubes, an outer vessel, and a SG bypass. The primary coolant enters the inlet of the SG and flows down through the shell side, forming a countercurrent flow with respect to the secondary feed water flow inside the tube. The secondary feed water enters the inlet of the SG tubes from the bottom, flows up through the helical tubes, and becomes a superheated steam at the outlet of the SG tubes.

PRHRS. The PRHRS of the VISTA-ITL facility is composed of a single train for the cooling system, which includes an emergency cooldown tank (ECT), a heat exchanger (HX), a makeup tank (MT), several valves, and the related piping. It is connected to both the feed water and the steam lines of the secondary system to provide a flow path for the natural circulation. The PRHRS is designed to have the same pressure drop and heat transfer characteristics and is arranged to have the same elevation and position as those of the reference system. 
The PRHRS makeup tank functions to make up the PRHRS inventory loss during the PRHRS operation. It was scaled down following the scaling ratios in Table 1 and was newly installed between the secondary system steam line and the PRHRS condensate line in parallel with the RRHRS heat exchanger.

Safety Injection System. The safety injection system was scaled down following the scaling ratios in Table 1 and was additionally installed in the VISTA-ITL facility. It included a refueling water tank (RWT), a safety injection pump (SIP), a charging pump, and the related piping, valves, and instruments.

Break Simulation System (BSS). The line breaks of SIS, SCS, and PSV were simulated by installing a break spool piece. The configuration of the spool piece is shown in Figure 2. It consists of a quick opening valve, a break nozzle, a case holding the break nozzle, and a few instruments. A pressure transducer and two thermocouples were installed both upstream and downstream of the break nozzle. The detailed geometry of the break nozzle for the present SBLOCA tests is shown in Figure 3. The break nozzle was designed according to the scaling law so that the coolant escapes from the primary system at the scaled-down break flow rate. The break nozzle was installed horizontally at the discharge line of the break points of the SIS, SCS, and PSV. The quick opening valve was opened within $0.5 \mathrm{~s}$ by the operators when the test was initiated. The break flow was discharged to the break measuring system (BMS). When a SBLOCA occurs, a choking is expected to occur at the break location during the whole SBLOCA scenario. The inner diameter of the break nozzle is determined to be $1.77 \mathrm{~mm}$, which corresponds to 1/787 of a 2-inch break area. The break nozzle has a wellrounded entrance and its length is fixed to $70 \mathrm{~mm}$ including the entrance region to comply with the long pipe requirement that the length-to-diameter ratio should be above 12 .

Break Measuring System (BMS). The break flow was discharged into a BMS, which consists of a separating vessel (SV1) and two measuring vessels (MV-1 and MV-2). The overall configuration of the break measuring system is shown in Figure 4 . The separating vessel is used to divide the break flow from the break points into steam and water flows. The steam, which is separated in the separating vessel, was discharged through a silencer into the atmosphere. The steam flow rate was measured by a vortex-type flow meter at the discharge line. The water, which was separated in the separating vessel, was drained to one of two measuring vessels. A load cell was installed on the bottom of each measuring vessel to weigh the water mass. The separated water was first introduced to MV01 . When MV-01 is full of water, the flow direction is switched from MV-01 to MV-02 by a 3-way valve. While MV-02 is used to measure the water mass, MV-01 is drained for the next usage and vice versa. The separating vessel is also designed to simulate a containment backpressure by controlling its pressure using a pressure control valve.

2.3.1. Instrumentation, Control, and Data Acquisition Systems. Figure 5 shows the schematics of the instrumentation and

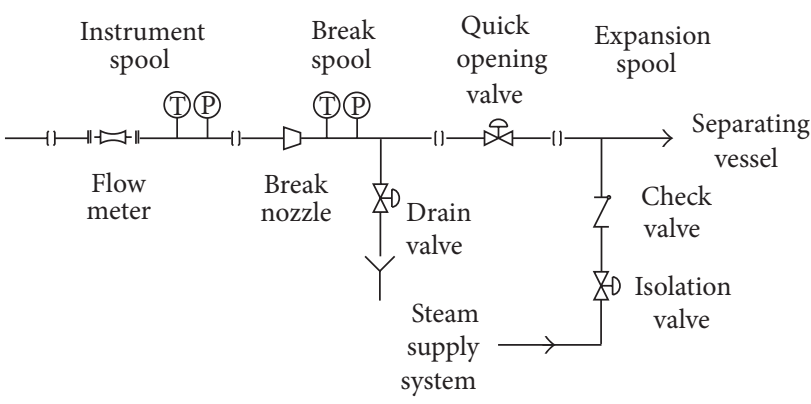

Figure 2: Configuration of the break simulation system.

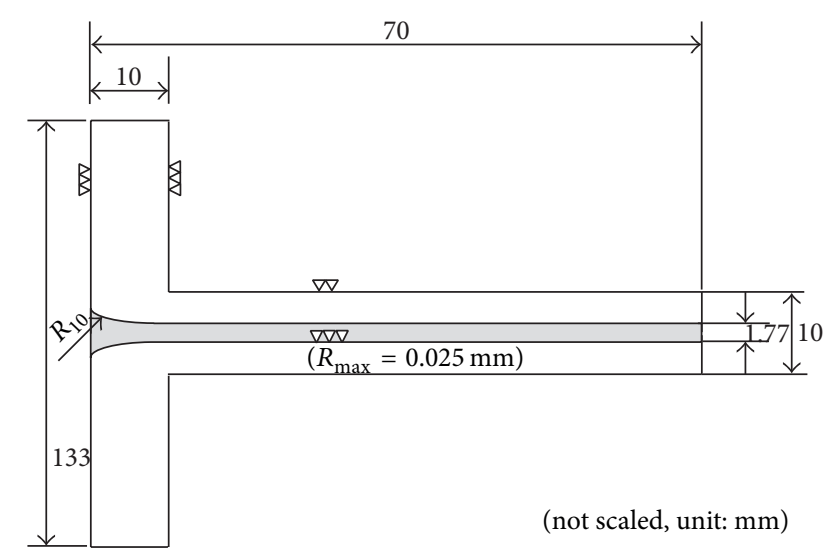

Figure 3: Detailed geometry of the break nozzle.

data acquisition system. The instrument system comprises a total of 246 measurement channels. It allows the measurement of all relevant thermal-hydraulic quantities of fluid systems such as a reactor pressure vessel, steam generators, a secondary system, and auxiliary systems. The instrument signals of the VISTA-ITL consist of an AI (analog input), an AO (analog output), a TC (thermocouple), a DI (digital input), a DO (digital output), and an SR (serial communication). They can also be categorized according to the instrument type such as the temperature, static pressure, differential pressure, water level, flow rate, mass, and power.

The VISTA-ITL was designed to be operated by a combination of manual and automatic operation. Several initial operations such as the inventory filling, startup, and cooldown are operated manually by an operator. Once the major thermal-hydraulic parameters reach a steady-state condition, they can be switched over to be controlled automatically by PID feedback control logics so as to maintain the achieved steady-state condition. The controlled components include an electrical heating rod, a main coolant pump, a feed water control valve, a steam pressure control valve, a feed water storage tank heater, and a makeup pump. A special combination of three heater groups is used to prevent the maximum heater surface temperature from exceeding the safety limit. The control system allows the simulation of timeor pressure-dependent parameters such as the core decay heat release and safety injection flow rates, respectively.

A high-performance data acquisition system is installed to acquire data from the instrument system. This system 


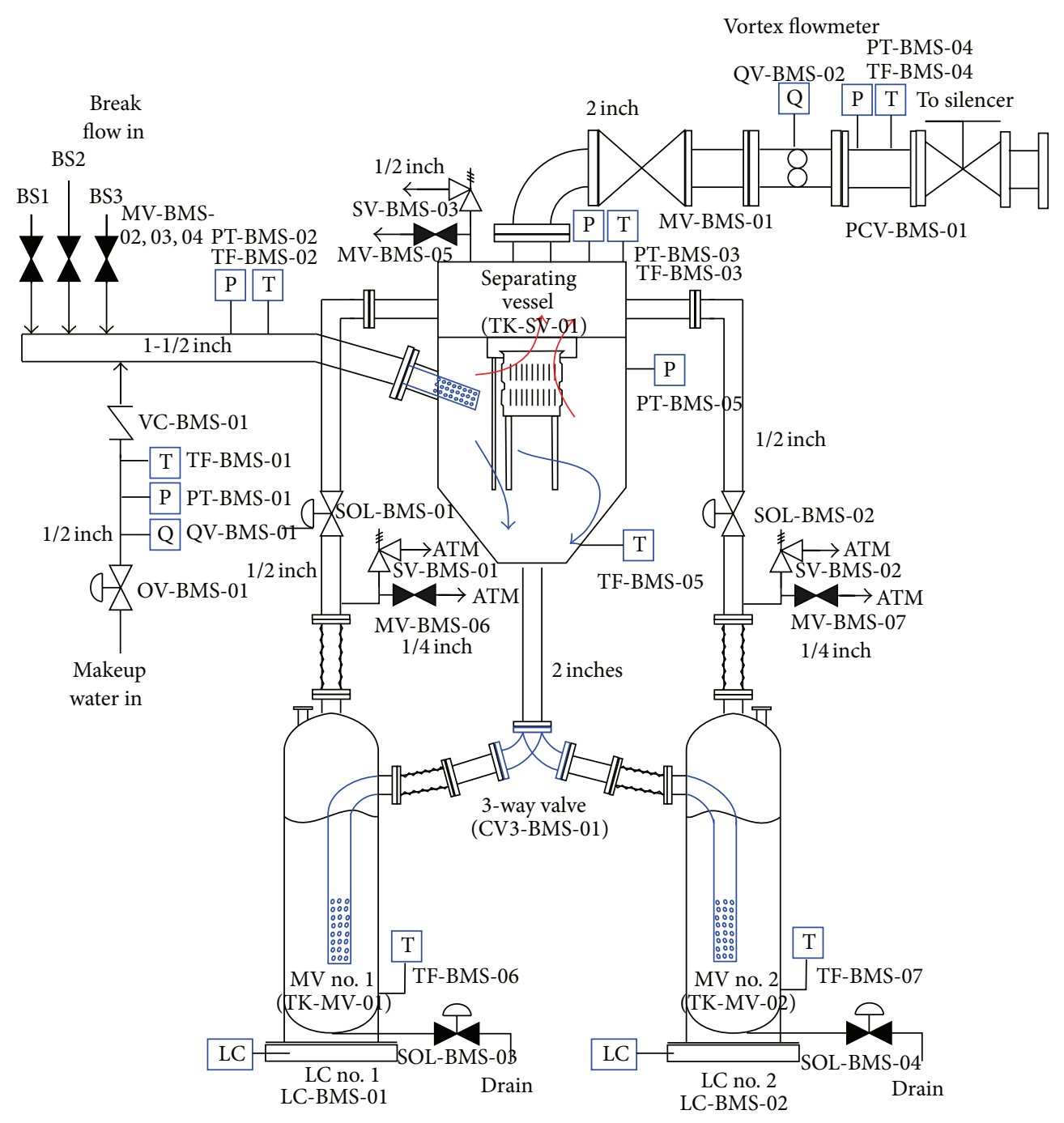

FIGURE 4: Schematic diagram of the break measuring system.

consists of two parts, a computer and display terminal, and the VXI C-size mainframe and terminal panels residing in the control room. These two parts are connected using an industry standard IEEE 1394 (Firewire) serial control and data interface. The data acquisition system is isolated from the control system using several types of signal distributors. The computer collects and saves data from various instruments measuring the pressure including the differential pressure, water level, flow rate, pump speed, and temperature.

\section{VISTA-ITL Program}

Several tests were conducted using the VISTA-ITL facility in support of the SMART design verification. Table 2 shows the brief summary of the test matrix of the VISTA-ITL program. All of them were done in the cause of the SMART standard design approval and technology validation program from 2009 through 2011. A set of tests for SBLOCAs, CLOF, and PRHRS performance were performed to understand the general behavior and assess the safety of the SMART design using the VISTA-ITL facility [7]. The test results were used to validate the TASS/SMR-S code.

Three SBLOCA tests were successfully performed and provided for validating the TASS/SMR-S code. The break types are guillotine breaks, and their break locations are at the safety injection system (SIS) line (nozzle part of the RCP discharge), at the suction line of the shutdown cooling system (SCS) (nozzle part of the RCP suction), and at the pressurizer safety valve (PSV) line connected to the pressurizer top. Additional SBLOCA tests were performed for various initial and boundary conditions with some facility modifications.

An integral effect test was successfully performed to provide data to assess the simulation capability of the TASS/SMR code for a complete loss of reactor coolant system (RCS) flow rate (CLOF) scenario for the SMART design. The steady-state conditions were achieved to satisfy the initial test conditions presented in the test requirement; its boundary conditions were accurately simulated, and the CLOF scenario in the SMART design was reproduced properly using the VISTAITL facility. 


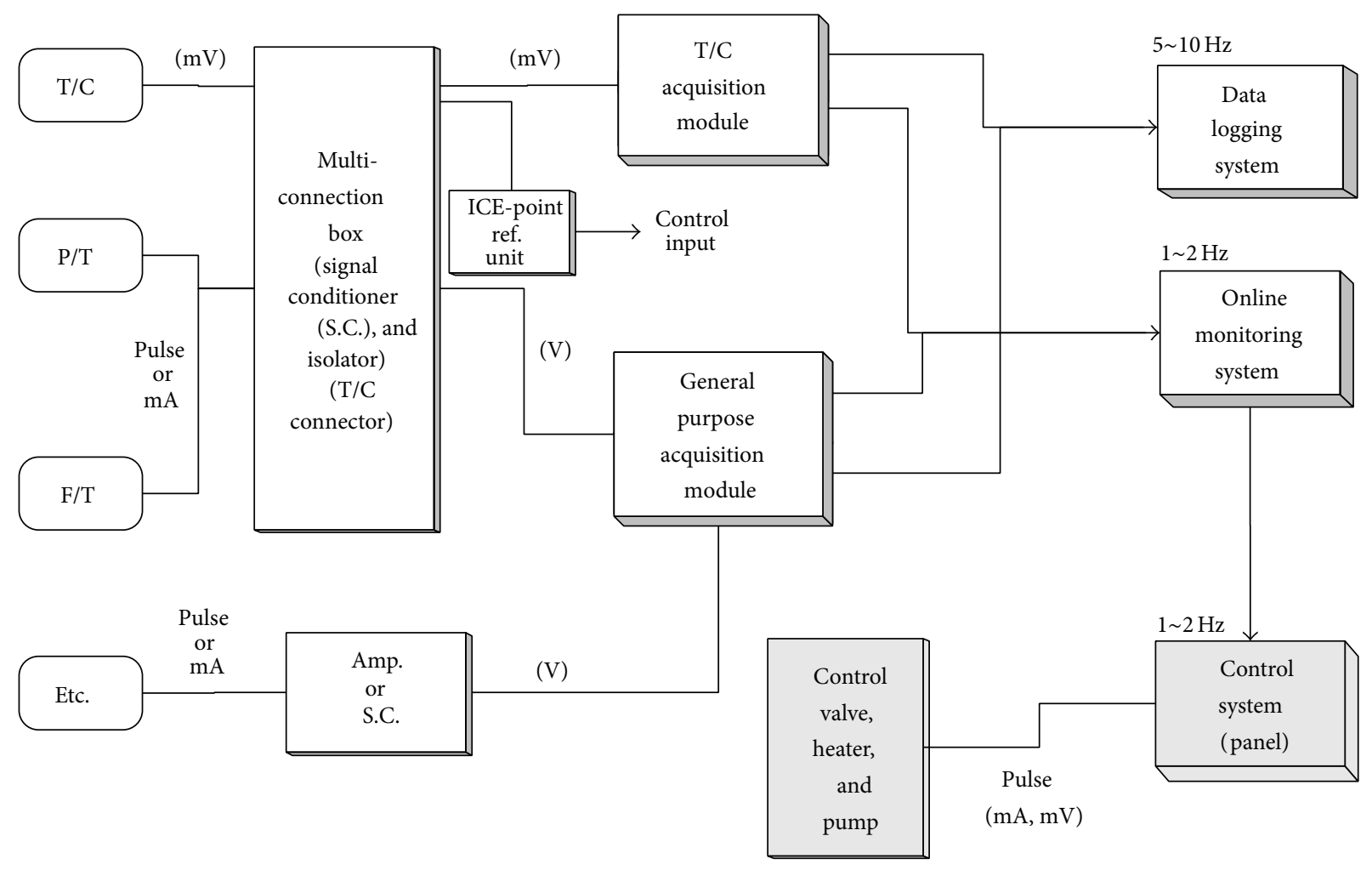

FIGURE 5: Schematics of the instrumentation and data acquisition system.

PRHRS performance verification tests were performed for $100 \%$ scaled power, $20 \%$ scaled power, and hot standby condition. It was demonstrated that two-phase natural circulation in the PRHRS was properly achieved at different initial powers and feed water flow rates. The PRHRS performance was also investigated for SBLOCA conditions. The experimental results show that the steady-state conditions were operated to satisfy the initial test conditions presented in the test requirement, and its boundary conditions were properly simulated. With the operation of PRHRS, a two-phase natural circulation flow formed inside the two-phase PRHRS natural circulation loop.

The VISTA-ITL program includes the test results on the SBLOCA, CLOF, and PRHRS performances and the analysis results on SMART and VISTA-ITL using the MARS-KS and TASS/SMR-S codes. The VISTA-ITL program contributed to the SMART SDA by providing proper test data for validating the TASS/SMR-S code.

\section{MARS-KS Simulation on a SBLOCA Scenario}

4.1. MARS Nodalization. Figures 6 and 7 show the MARSKS [4] nodalization schemes used for the SMART design and VISTA-ITL, respectively. The nodalization schemes of both the SMART design and the VISTA-ITL include all the reactor coolant systems, a safety injection system, a secondary system, PRHRS, and auxiliary systems. While the SMART design has four loops, the VISTA-ITL has a single loop. The overall nodalization was configured to provide consistency between them.

4.2. Pretest Analysis of a SBLOCA Scenario on SMART and VISTA-ITL. A SBLOCA scenario for both the reference plant SMART and the VISTA-ITL has been analyzed using the bestestimate system code, MARS-KS [4].

4.2.1. Steady-State Calculation Results. Table 3 shows the design parameters and calculated major design parameters of the SMART design, SMART calculation, and VISTA-ITL calculations under a steady-state condition. In the VISTAITL facility, the actual design values are different from the ideally scaled-down values. The main source of the distortion is considered to be caused by a large heat structure owing to the inherent nature of a small-scale integral effect test facility such as VISTA-ITL. To assess the scaling distortion owing to the restraints of the actual VISTA-ITL design, three calculations were performed. One is a case in which the actual design of the VISTA-ITL was simulated (VISTA-Actual), the second one was a case in which the ideally calculated design of the VISTA-ITL was simulated (VISTA-Ideal), and the last one was a case in which the actual design values of the VISTAITL were simulated except for the ideally scaled-down heat structure (VISTA-Ideal HS). The MARS calculation results showed good agreement with the SMART design within an allowable uncertainty bound, as shown in Table 3 .

4.2.2. Transient Calculation Results. The safety injection line break is considered to be a typical SBLOCA scenario. The 
TABLE 2: Test matrix of the VISTA-ITL program.

\begin{tabular}{|c|c|c|c|}
\hline Test type & Test ID & Date & Objectives \\
\hline \multirow{3}{*}{ SBLOCA phase I } & SB-SIS-06 & December 2010 & $\begin{array}{l}\text { Safety injection system (SIS) line break SBLOCA and RCP } \\
\text { discharge }\end{array}$ \\
\hline & SB-SCS-01 & December 2010 & $\begin{array}{l}\text { Shutdown cooling system (SCS) line break SBLOCA and RCP } \\
\text { suction }\end{array}$ \\
\hline & SB-PSV-01 & December 2010 & $\begin{array}{l}\text { Pressurizer safety valve (PSV) line break SBLOCA and pressurizer } \\
\text { top }\end{array}$ \\
\hline \multirow{4}{*}{ PRHRS performance } & PRHRS-SS-N1 & April 2011 & $\begin{array}{l}\text { PRHRS actuation during the steady state operation with } 100 \% \\
\text { power }\end{array}$ \\
\hline & PRHRS-SS-N2 & April 2011 & $\begin{array}{l}\text { PRHRS actuation during the steady state operation with } 20 \% \\
\text { power }\end{array}$ \\
\hline & PRHRS-SS-N3 & April 2011 & $\begin{array}{l}\text { PRHRS actuation during the steady state operation under hot } \\
\text { standby condition }\end{array}$ \\
\hline & PRHRS-TR-A3 & May 2011 & PRHRS actuation during the transient operation of SBLOCA \\
\hline \multirow{2}{*}{$\begin{array}{l}\text { Complete loss of RCS } \\
\text { flow rate }\end{array}$} & CLOF-01 & July 2011 & Complete loss of RCS flow rate \\
\hline & CLOF-02 & July 2011 & Complete loss of RCS flow rate (repetition) \\
\hline \multirow{3}{*}{$\begin{array}{l}\text { SBLOCA phase II } \\
\text { (after hardware } \\
\text { modification) }\end{array}$} & SB-SIS-07 & April 2011 & $\begin{array}{l}\text { Safety injection system (SIS) line break SBLOCA and RCP } \\
\text { discharge (repetition) }\end{array}$ \\
\hline & SB-SCS-04 & November 2011 & $\begin{array}{l}\text { Shutdown Cooling System (SCS) line break SBLOCA and RCP } \\
\text { suction (repetition) }\end{array}$ \\
\hline & SB-PSV-02 & October 2011 & $\begin{array}{l}\text { Pressurizer safety valve (PSV) line break SBLOCA and pressurizer } \\
\text { top (repetition) }\end{array}$ \\
\hline
\end{tabular}

TABLE 3: Comparison of the major parameters under a steady state condition.

\begin{tabular}{|c|c|c|c|c|c|c|}
\hline \multirow{2}{*}{ Parameter } & \multicolumn{2}{|c|}{ SMART design value } & \multicolumn{4}{|c|}{ MARS results for VISTA-ITL } \\
\hline & SMART & VISTA-Ideal & SMART & VISTA-Actual & VISTA-Ideal & VISTA-Ideal HS \\
\hline \multicolumn{7}{|c|}{ Primary side } \\
\hline Power [MWt] & 330 & 0.419 & 330.0 & 0.419 & 0.419 & 0.419 \\
\hline PZR pressure $[\mathrm{MPa}]$ & 15.0 & 15.0 & 15.0 & 15.0 & 15.0 & 15.0 \\
\hline 1st flow rate $[\mathrm{kg} / \mathrm{s}]$ & 2090 & 2.66 & 2079.2 & 2.66 & 2.66 & 2.66 \\
\hline SG 1st inlet temp. $\left[{ }^{\circ} \mathrm{C}\right]$ & 323 & 323 & 323 & 323 & 323 & 323 \\
\hline SG 1st outlet temp. $\left[{ }^{\circ} \mathrm{C}\right]$ & 295.7 & 295.7 & 295 & 296 & 296 & 296 \\
\hline \multicolumn{7}{|c|}{ Secondary side } \\
\hline SG 2nd inlet press. [MPa] & 6.0 & 6.0 & 6.0 & 6.0 & 6.0 & 6.0 \\
\hline SG 2 nd outlet press. [MPa] & 5.2 & 5.2 & 5.2 & 5.2 & 5.2 & 5.2 \\
\hline Feed water flow rate $[\mathrm{kg} / \mathrm{s}]$ & 160.8 & 0.204 & 160.8 & 0.201 & 0.204 & 0.204 \\
\hline Feed water temp. $\left[{ }^{\circ} \mathrm{C}\right]$ & 200.0 & 200.0 & 200.0 & 200.0 & 200.0 & 200.0 \\
\hline Steam temp. $\left[{ }^{\circ} \mathrm{C}\right]$ & 298.0 & 298.0 & 291.0 & 307.2 & 298.7 & 298.7 \\
\hline
\end{tabular}

broken safety injection line was assumed to be one of the available safety lines, and only one of the four safety injections is active for the transient calculation based on a single failure assumption. The safety injection flow rate of the VISTA-ITL is scaled down by applying the appropriate scaling ratios to the SMART design. The break area was set to be reduced according to the scale ratio of the flow rate since the break flow would be choked during the SBLOCA simulation.

Table 4 shows the major sequence of events observed during the present analysis. The thermal-hydraulic behavior occurs 1.664 times faster in the VISTA-ITL than in the SMART design, as shown in Table 1 . Based on the simulation results for the SMART design, the major sequence of events can be explained as follows. When one of four safety injection lines was broken, the RCS began to be depressurized. As the pressurizer pressure reached the low pressurizer pressure (LPP) trip set point $\left(\mathrm{P}_{\mathrm{LPP}}\right) 285.5 \mathrm{~s}$ after the break, the reactor tripped with the reactor trip signal, which was generated $1.1 \mathrm{~s}$ after the LPP signal. Concurrently with the reactor trip signal, the injection of the feed water stopped and the main steam isolation valves were closed. A PRHRS actuating signal was generated at $287.7 \mathrm{~s}$ after the break. The PRHRS isolation valves were opened $292.7 \mathrm{~s}$ after the break with a $5 \mathrm{~s}$ delay. The main steam isolation valves were closed $15 \mathrm{~s}$ after the PRHRS actuation signal, which corresponds to $302.7 \mathrm{~s}$ after the break. With the operation of PRHRS, a two-phase natural circulation occurred inside the PRHRS. The decay heat generated from the reactor core was transferred through 


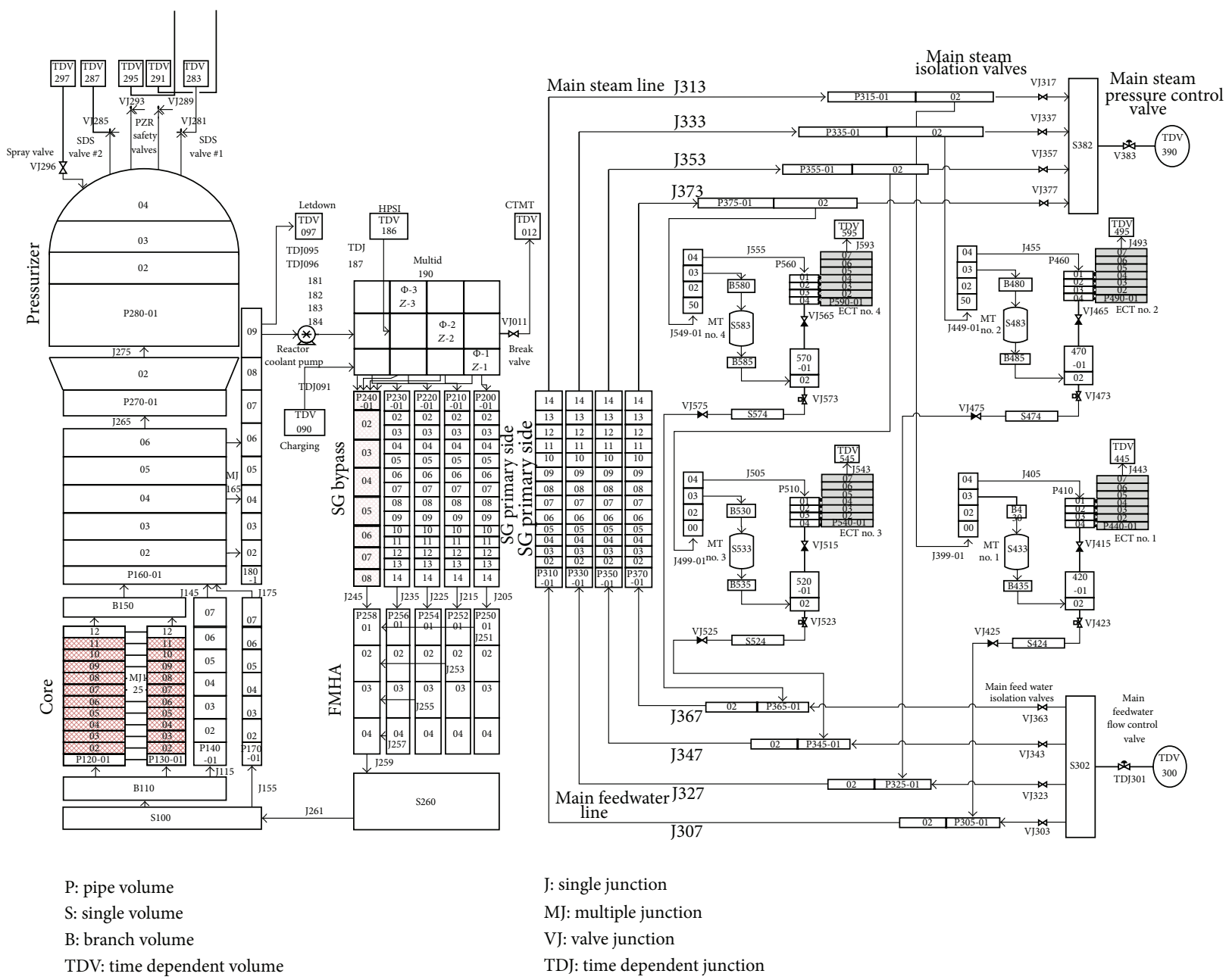

FIGURE 6: MARS nodalization for the SMART design.

the SG and was eventually removed by the PRHRS heat exchanger located in a water-filled ECT. After that, the safety injection actuation signal (SIAS) was generated $489.2 \mathrm{~s}$ after the break, and the safety injection water was injected $30 \mathrm{~s}$ after the SIAS.

When the calculation results of the SMART design are compared with those of the VISTA ITL, the SMART calculation time should be divided by 1.664 for a comparison. For all three calculations of VISTA-ITL, the sequence progressed very similarly compared with that of the SMART design during the initial sequence of events, as shown in Table 4.

Figure 8 show comparison results of the pressurizer pressure during the safety injection line break accidents, which is a typical SBLOCA scenario. The same core power curve was applied in all four calculations, and the safety injection water was supplied according to the order of the pressure reduction. Compared with the SMART design calculation, the pressures of all three VISTA-ITL calculations were reduced faster at an earlier period, and their behavior was very similar in the three calculations. About $450 \mathrm{~s}$ (based on the VISTA-ITL time scale) after the break, the calculated pressure of VISTAITL-Actual design decreased more slowly than the SMART design calculation. This is because the VISTA ITL facility has a relatively large heat structure compared to the SMART design. When the heat structure was scaled down ideally in the VISTA ITL-Ideal HS, the calculation results showed a very good agreement with those calculations in the VISTA ITL-Ideal. The safety injection signal was actuated when the RPV pressure became lower than the safety injection set point of $\mathrm{P}_{\text {SIAS }}$. As shown in Table 4, the pressure reduction of the reactor vessel was the fastest (287.0 s after the break) during the VISTA ITL-Actual calculation, followed by VISTA ITLideal HS calculation (313.2 s after the break), VISTA ITLIdeal calculation (317.5 s after the break), and the SMART design calculation (398.8 s after the break). The pressure tendency of the reactor pressure vessel was similar to the pressure changes of the pressurizer. In addition, it should be noted that the safety injection flow rates of the VISTA ITL-Actual design calculation was less than that in the other calculations owing to higher system pressures during the latter period.

From the present similarity analysis, the thermal-hydraulic similarity between the SMART design and the VISTA-ITL facility was ascertained. In addition, the similarity analysis calculations provided a good insight into the unique features 


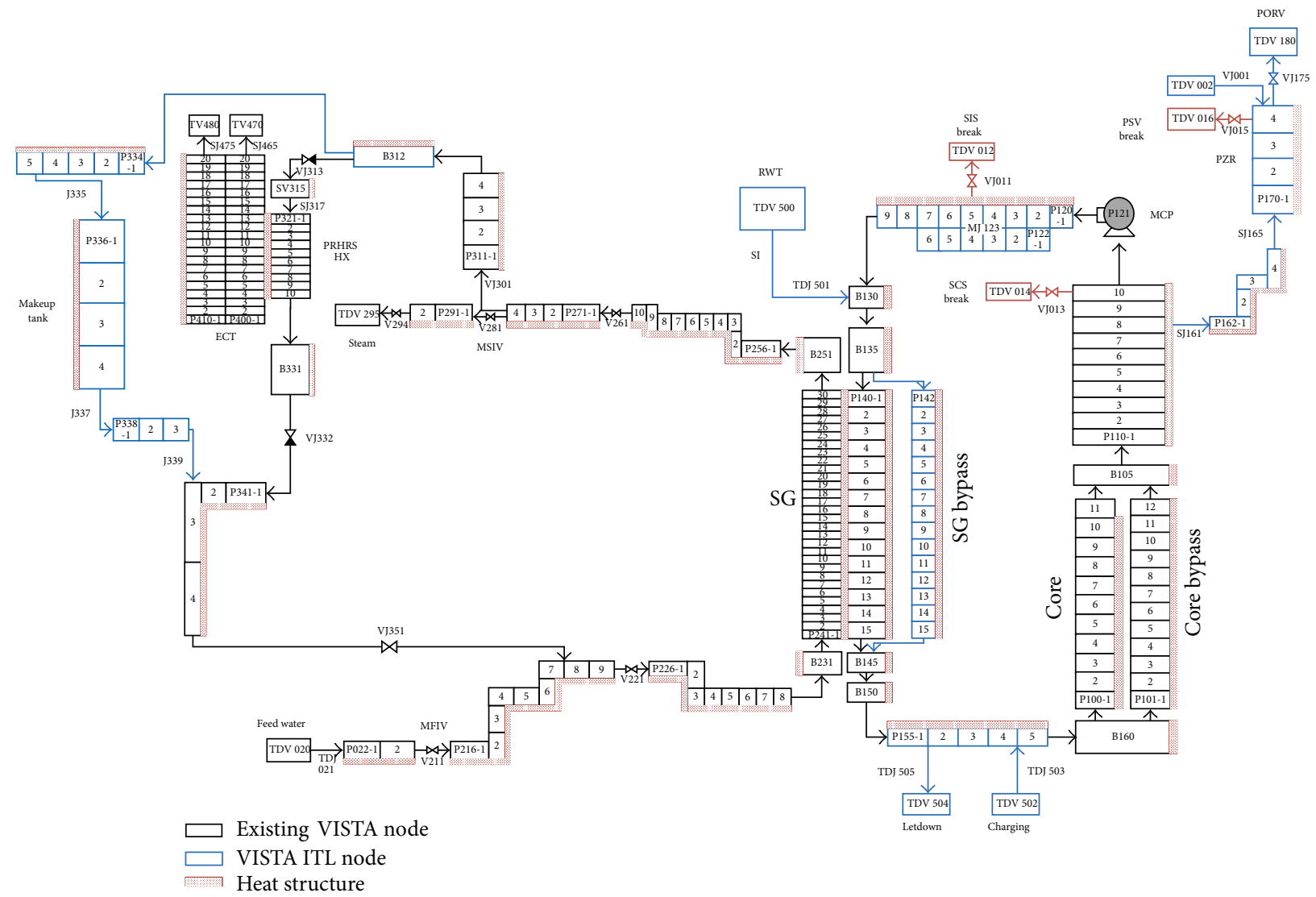

FIGURE 7: MARS nodalization for the VISTA-ITL facility.

TABLE 4: Major sequence of events for SBLOCA.

\begin{tabular}{|c|c|c|c|c|c|c|}
\hline \multirow[b]{2}{*}{ Event } & \multicolumn{2}{|c|}{ Set points/time delay } & \multicolumn{4}{|c|}{ Time (seconds) } \\
\hline & SMART & VISTA ITL-Ideal & $\begin{array}{c}\text { SMART } \\
\text { (VISTA-equivalent) }\end{array}$ & VISTA-Actual & VISTA-Ideal & VISTA-Ideal HS \\
\hline Break & - & - & 0 & 0 & 0 & 0 \\
\hline Reach LPP set point & PZR pres. $=P_{\mathrm{LPP}}$ & PZR pres. $=P_{\mathrm{LPP}}$ & $\begin{array}{l}285.5 \\
(171.6)\end{array}$ & 129.0 & 142.1 & 140.2 \\
\hline $\begin{array}{l}\text { LPP reactor trip signal } \\
\text { (i) FW Stop } \\
\text { (ii) Pump coast down }\end{array}$ & $1.1 \mathrm{~s}$ delay & $0.66 \mathrm{~s}$ delay & $\begin{array}{l}286.6 \\
(172.3)\end{array}$ & 129.7 & 142.7 & 140.9 \\
\hline Reactor trip-curve start & $1.6 \mathrm{~s}$ after LPP & $0.96 \mathrm{~s}$ after LPP & $\begin{array}{c}287.1 \\
(172.6)\end{array}$ & 130.0 & 143.0 & 141.2 \\
\hline $\begin{array}{l}\text { PRHR actuation signal } \\
\text { (PRHRSAS) }\end{array}$ & $2.2 \mathrm{~s}$ after LPP & $1.32 \mathrm{~s}$ after LPP & $\begin{array}{l}287.7 \\
(172.9)\end{array}$ & 130.3 & 143.4 & 141.5 \\
\hline PRHRS IV open & 5 s delay & 3 s delay & $\begin{array}{l}292.7 \\
(175.9)\end{array}$ & 133.3 & 146.4 & 144.5 \\
\hline MSIV/FIV close & $15 \mathrm{~s}$ delay & 9.01 s delay & $\begin{array}{l}302.7 \\
(181.9)\end{array}$ & 139.0 & 152.4 & 150.6 \\
\hline $\begin{array}{l}\text { Safety injection signal } \\
\text { (SIAS) }\end{array}$ & BPV pres. $=P_{\text {SIAS }}$ & BPV pres. $=P_{\text {SIAS }}$ & $\begin{array}{c}663.6 \\
(398.8)\end{array}$ & 287.0 & 317.5 & 313.2 \\
\hline Safety injection start & 30 s delay & 18.03 s delay & $\begin{array}{l}693.6 \\
(416.8)\end{array}$ & 305.0 & 335.5 & 331.2 \\
\hline Test end & - & - & $\begin{array}{c}7000 \\
(4206.7)\end{array}$ & 4300 & 4300 & 4300 \\
\hline
\end{tabular}


TABLE 5: Comparison of the major parameters under a steady-state condition.

\begin{tabular}{|c|c|c|c|c|}
\hline Parameter & SMART (design value) & VISTA-ITL (ideal value) & VISTA-ITL (test data) & VISTA-ITL (MARS) \\
\hline Power [MWt] & 330.0 & 0.432 & 0.4504 & 0.4504 \\
\hline PZR pres. $[\mathrm{MPa}]$ & 15.0 & 15.0 & 14.98 & 14.98 \\
\hline 1st flow rate $[\mathrm{kg} / \mathrm{s}]$ & 2090.0 & 2.65 & 2.613 & 2.6216 \\
\hline SG 1st inlet $T .[\mathrm{K}]$ & 596.15 & 596.15 & 596.75 & 598.96 \\
\hline SG 1st outlet $T$. [K] & 568.85 & 568.85 & 568.85 & 571.62 \\
\hline FW flow rate $[\mathrm{kg} / \mathrm{s}]$ & 160.8 & 0.204 & 0.152 & 0.153 \\
\hline FW temp. [K] & 473.15 & 473.15 & 326.45 & 325.15 \\
\hline SG 2nd inlet $P[\mathrm{MPa}]$ & 6.0 & 6.0 & 5.95 & 5.98 \\
\hline SG 2 nd outlet $P[\mathrm{MPa}]$ & 5.2 & 5.2 & 5.19 & 5.22 \\
\hline
\end{tabular}

of the VISTA-ITL and the thermal-hydraulic characteristics of the SMART design.

4.3. Posttest Simulation of a SBLOCA Test Using VISTA-ITL. A posttest simulation on a SBLOCA test for the shutdown cooling system line break (SB-SCS-04) has been performed with the MARS-KS code to assess its simulation capability for the SBLOCA scenario of the SMART design.

4.3.1. A Typical SBLOCA Test (SB-SCS-04). As a shutdown cooling system (SCS) line is broken in the SMART design, the primary system pressure decreases with the discharge of the coolant through the break. When the primary pressure reaches the low pressurizer pressure (LPP) set point, the reactor trip signal is generated with a $1.1 \mathrm{~s}$ (in VISTA-ITL: $0.66 \mathrm{~s})$ delay. As the turbine trip and loss of off-site power (LOOP) are assumed to occur consequently after the reactor trip, the LOOP occurs, the feed water is not supplied, and the RCP begins to coast down. With an additional $0.5 \mathrm{~s}$ (in VISTA-ITL: $0.3 \mathrm{~s}$ ) delay, the control rod is inserted. When the PRHRS actuation signal is generated by the low feed water flow rate $2.2 \mathrm{~s}$ (in VISTA-ITL: $1.32 \mathrm{~s}$ ) after the LPP, the SG is isolated from the turbine by the isolation of the main steam and feed water isolation valves and is connected to the PRHRS. The safety injection actuation signal was generated when the RCS pressure reaches below the safety injection actuation signal, and the SI water is injected with a time delay of $30 \mathrm{~s}$ (in VISTA-ITL: $18.03 \mathrm{~s}$ ). The break nozzle diameter is $50 \mathrm{~mm}$ in the SMART design and the scaled-down value is $1.77 \mathrm{~mm}$ in the VISTA-ITL. The set points of LPP and SIAS were 12.3 and $10.0 \mathrm{MPa}$, respectively.

4.3.2. Steady-State Calculation Results. Table 5 shows a comparison of the major parameters of the SMART design, the ideal value, test data, and MARS-KS calculation results of VISTA-ITL at $103 \%$ rated power condition. The simulation results show that most of the thermal-hydraulic parameters agree well with one another. The heat loss of about $19 \mathrm{~kW}$ was estimated and added during the test. The feed water flow rate is lower during the test than the ideal value owing to the low injected feed water temperature to match the heat balance.

4.3.3. Transient Calculation Results. Table 6 shows the major sequence of events for the SB-SCS-04 test, and Figure 9

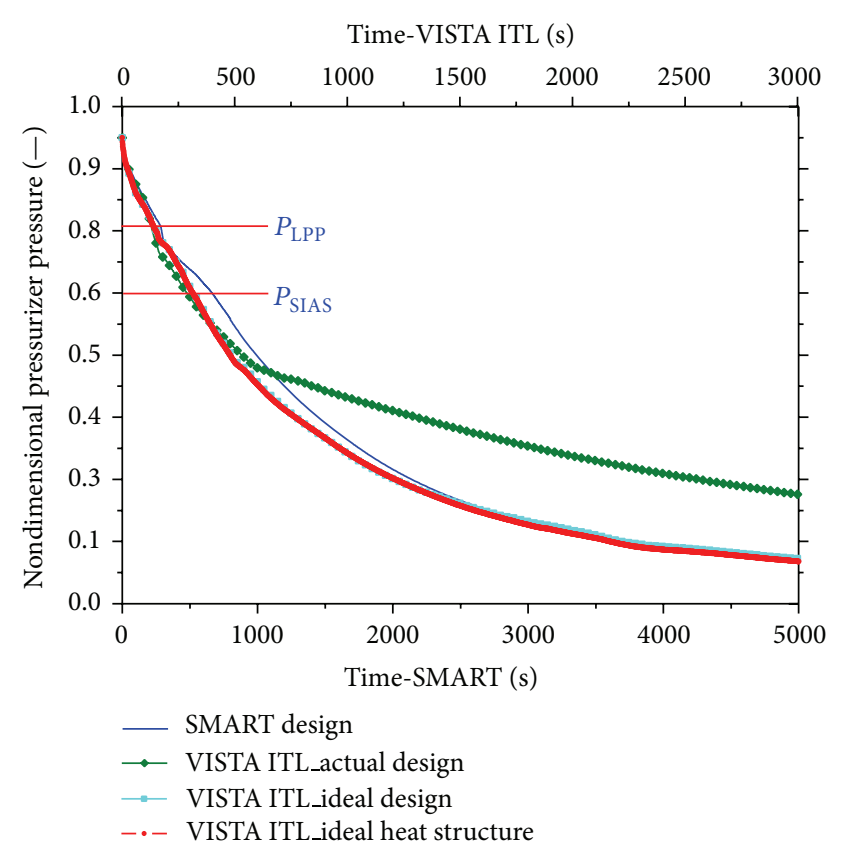

FIgURE 8: Comparison of calculated pressurizer pressures during the pretest simulation.

through Figure 15 show the variations of the major parameters of the core power, pressurizer pressure, and flow rates of the reactor coolant system (RCS) and break. The decay power curve and safety injection flow rate are successfully given for both the test and the simulation.

The core power was well simulated as a boundary condition during the MARS-KS calculation, as shown in Figure 9 . The primary pressure decreased rapidly during the single-phase blow-down period, as shown in Figure 10. As the depressurization is faster in the MARS-KS simulation, the LPP-related events occur about $15 \mathrm{~s}$ earlier than in the test. The overall trend of the primary pressure behavior is well simulated during the initial period and the plateau region. However, the decreasing rate becomes higher after the plateau. After a certain interval of abrupt pressure drop, the decreasing rate slows down and becomes higher at the later period after $938 \mathrm{~s}$. As the pressure decreased rapidly during the initial period before the safety injection signal, the safety injection signal was generated about $102.2 \mathrm{~s}$ earlier in 
TABLE 6: Major sequence of events for SBLOCA.

\begin{tabular}{|c|c|c|c|c|}
\hline Event & $\begin{array}{c}\text { Time } \\
\text { SMART design }\end{array}$ & $\begin{array}{c}\text { Time } \\
\text { VISTA-ITL }\end{array}$ & $\begin{array}{c}\text { Time (s) } \\
\text { Measured VISTA-ITL }\end{array}$ & $\begin{array}{c}\text { Time (s) } \\
\text { Calculated VISTA-ITL }\end{array}$ \\
\hline Break occurrence & 0.0 & 0.0 & 0.0 & 0.0 \\
\hline LPP set point & LPP & LPP & 131 & 116.1 \\
\hline LPP reactor trip signal & $\mathrm{LPP}+1.1 \mathrm{~s}$ & $\mathrm{LPP}+0.66 \mathrm{~s}$ & 132 & 118.1 \\
\hline Reactor trip signal-urve start & $L P P+1.6 s$ & $\mathrm{LPP}+0.96 \mathrm{~s}$ & 132 & 118.4 \\
\hline PRHRS actuation signal & $\mathrm{LPP}+2.2 \mathrm{~s}$ & $\mathrm{LPP}+1.32 \mathrm{~s}$ & 133 & 118.8 \\
\hline PRHRS IV full open & PRHRSAS $+5.0 \mathrm{~s}$ & PRHRSAS $+3 s$ & 136 & 121.1 \\
\hline SI signal & SIAS & SIAS & 475 & 372.8 \\
\hline SI start & SIAS $+30 s$ & SIAS $+18 s$ & 502 & 395.8 \\
\hline
\end{tabular}

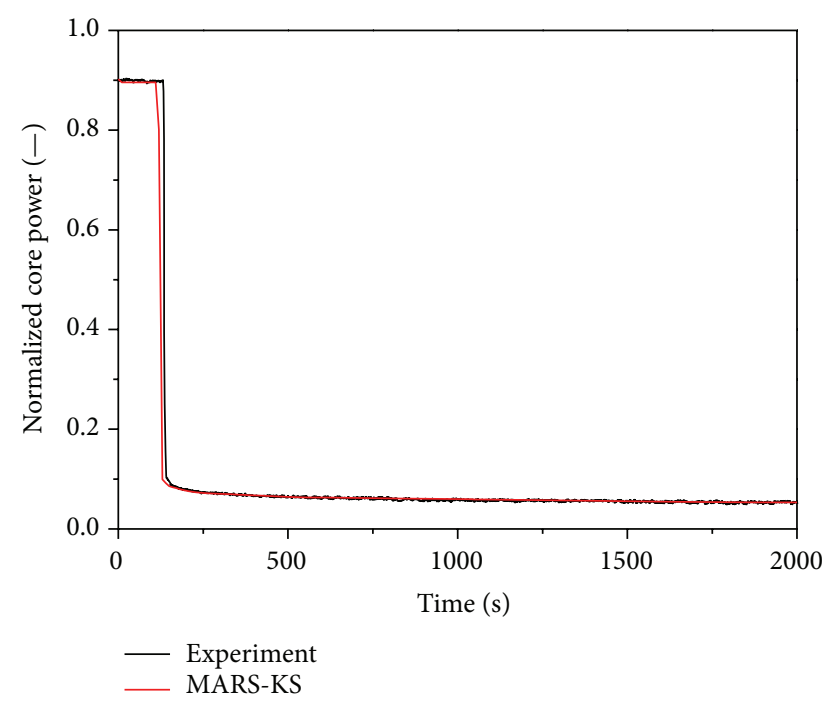

FIGURE 9: Comparison of calculation results with the test data: core power.

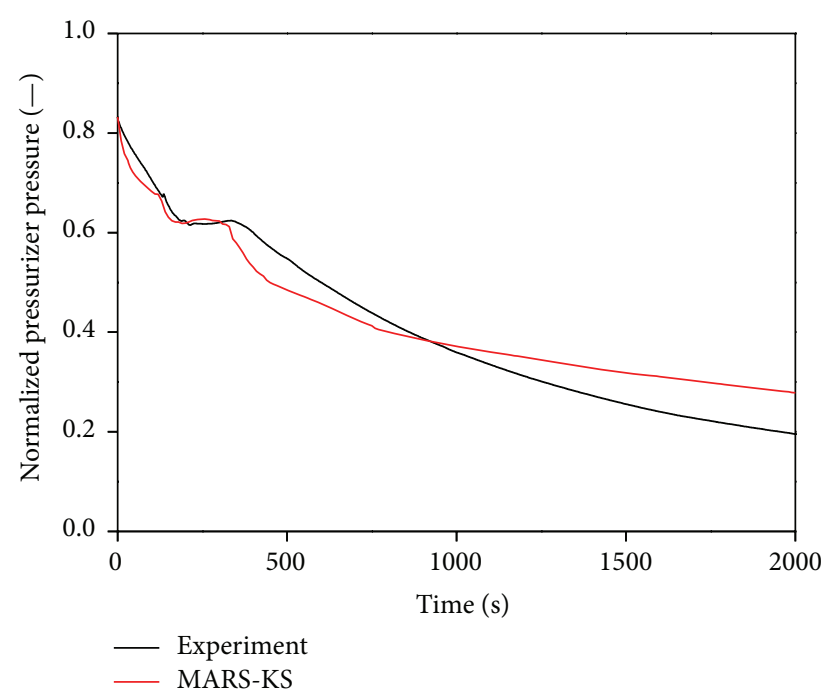

FIgURE 10: Comparison of calculation results with the test data: pressurizer pressure.

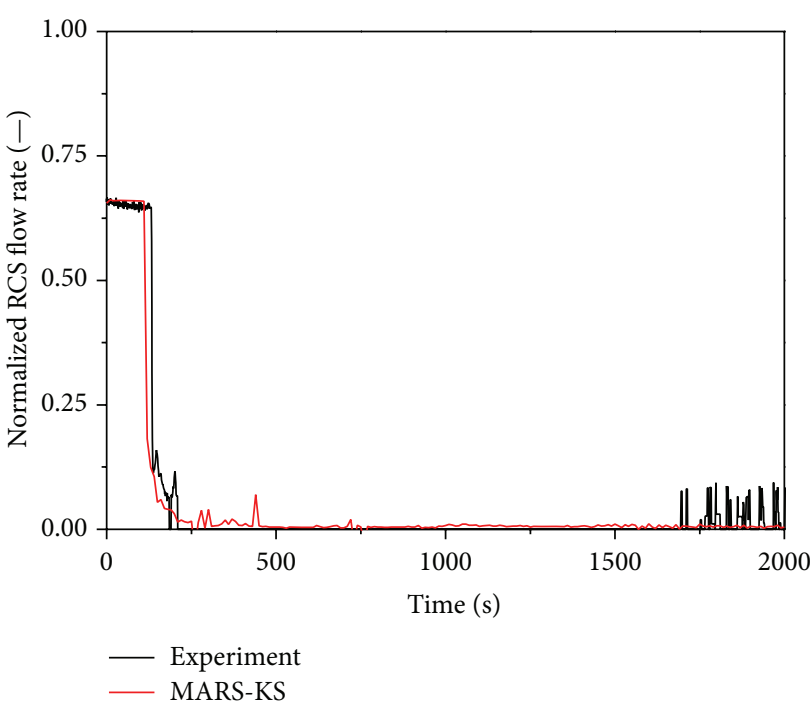

FIgURE 11: Comparison of calculation results with the test data: RCS flow rate.

the simulation than that in the experiment. The slow pressure decrease during the later period seems to be due to the high amount of heat structure in the small-scale integral effect test facility of VISTA-ITL.

The simulated RCS flow rate was in good agreement with the test data during the considered period of about 2,000 s, as shown in Figure 11. In the present simulation, a discharge coefficient of 0.6 was used to match the initial break flow rate of the SB-SCS-04 test. A typical trend of the break flow rate consists of three periods: single-phase water, two-phase mixture, and single-phase steam. As shown in Figure 12, the plateau region in the simulation seemed to be similar to that in the test. Figure 13 shows a comparison of the calculation results with the test data of the RPV level. In the earlier region, the RPV level decreases faster in the simulation than in the test. It is considered that a small amount of pressurizer inventory is held up in the pressurizer bottom and surge line.

As shown in Figure 14, the primary temperatures measured in the inlet and outlet of the steam generator decreased steadily for the whole simulation time because the decay heat 


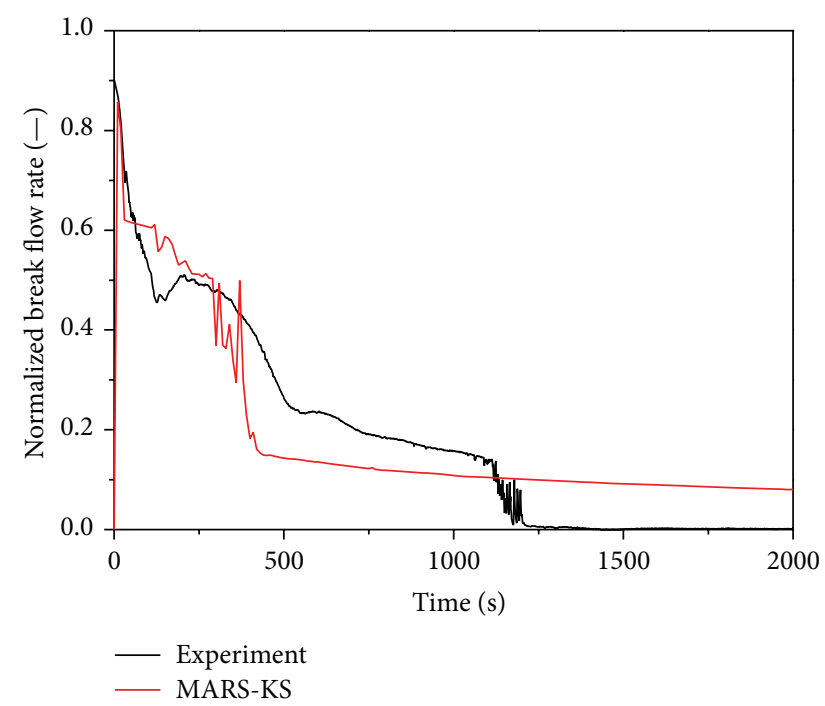

FIGURE 12: Comparison of calculation results with the test data: break flow rate.

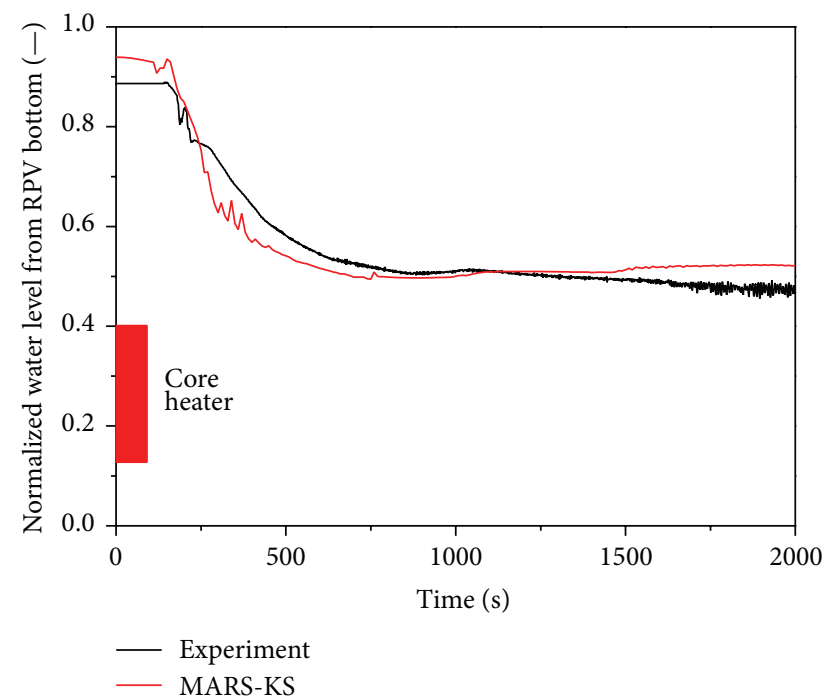

FIGURE 13: Comparison of calculation results with the test data: RPV level.

of the primary side could be removed by the PRHRS. This means that the PRHRS was operated well during both the test and the simulation. The trends of the simulated primary temperatures were in good agreement with the test data during the initial period but they become different during the later period. In the MARS-KS code, a slow natural circulation flow is formed in the primary system, but in the test both regions of the heater (source) and steam generator (sink) became separated. Figure 15 shows the typical secondary flow rate behaviors. The initial flow rate decreases as the PRHRS is operated. The MARS-KS code overestimates the experimental data during the initial period, but it matches well with the experimental data 500 seconds after the test start.

In the present simulation, the similarity between the VISTA-ITL data and its simulation results was good for the
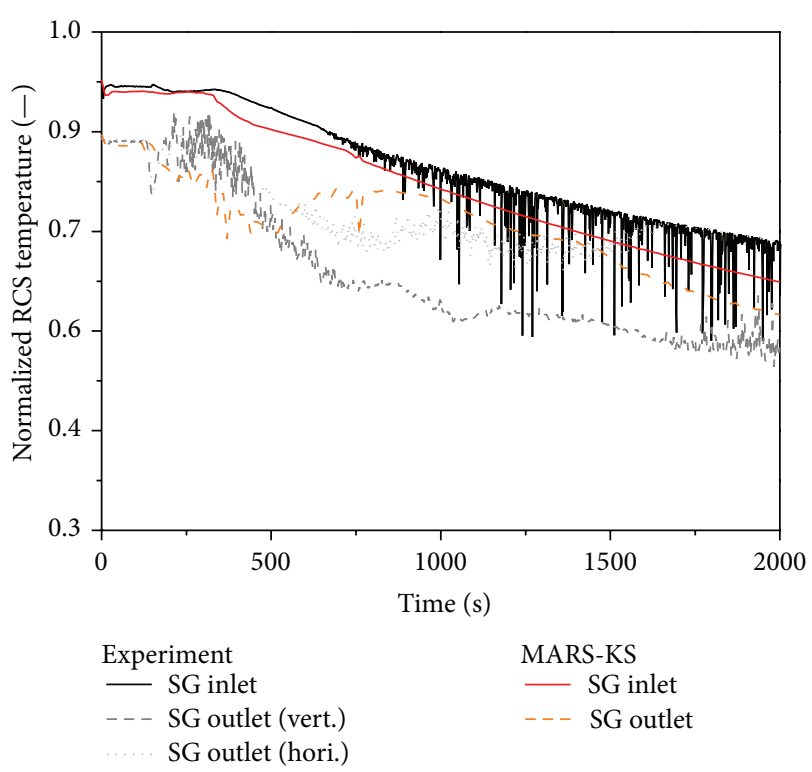

FIGURE 14: Comparison of the calculation results with the test data: primary temperature.

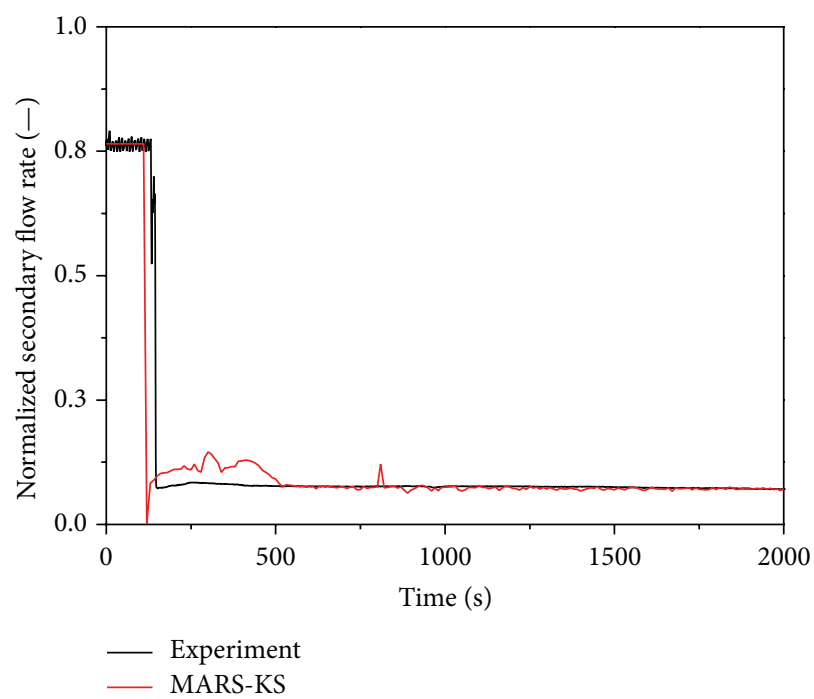

FIGURE 15: Comparison of calculation results with the test data: secondary flow rate.

major thermal-hydraulic parameters, as described in Figures 9-15.

\section{Summary and Conclusions}

A thermal-hydraulic integral effect test facility, VISTA-ITL, was introduced for the SMART design with a discussion of its scientific design characteristics; the similarity between the SMART design and the VISTA-ITL facility was analyzed using the MARS-KS code; and the VISTA-ITL test program was briefly introduced. The VISTA-ITL is a smallscale integral effect test facility and has the following characteristics: 1/2.77-height, 1/1310-volume, and full pressure 
and temperature simulation of SMART. Several tests on the SBLOCA, CLOF, and PRHRS performance were conducted using the VISTA-ITL facility in support of the SMART design verification. The VISTA-ITL program contributed to the SMART design licensing by providing proper test data for validating the system analysis code.

A typical SBLOCA scenario of the safety injection line break accident was analyzed using the MARS-KS code to ascertain the thermal-hydraulic similarity between the SMART design and the VISTA-ITL facility, and the similarity analysis results provided good insight into the unique design features of the VISTA-ITL and the thermal-hydraulic characteristics of the SMART design. In addition, a SBLOCA test for the shutdown cooling system line break was performed, and the test was simulated with the MARS-KS code, to assess its simulation capability for the SBLOCA scenario of the SMART design. The SBLOCA scenario in the SMART design was well reproduced using the VISTA-ITL facility, and the measured thermal-hydraulic data were properly simulated with the MARS-KS code. The present SBLOCA test and analysis results can provide a comprehensive understanding on the thermal-hydraulic characteristics of the SBLOCA behavior of the SMART design.

The VISTA-ITL facility could be used for further understanding of the full-power thermal-hydraulic behaviors for the SMART design together with the FESTA facility [12], which is a full-height integral effect test facility having the capability of simulating the multidimensional and multitrain effects for the SMART design.

\section{Nomenclature}

ATLAS: Advanced thermal-hydraulic test loop for accident simulation (facility)

BMS: $\quad$ Break measuring system

BSS: $\quad$ Break simulation system

FWST: $\quad$ Feed water supply tank

IET: $\quad$ Integral effect test

ITL: Integral test loop

KAERI: Korea Atomic Energy Research Institute

LPP: $\quad$ Low pressure pressurizer

MARS-KS: A best-estimate, multidimensional, thermal-hydraulics system code

MCP: $\quad$ Main coolant pump

MV: $\quad$ Measuring vessel

PRHRS: Passive residual heat removal system

PSV: $\quad$ Pressurizer safety valve

RCS: $\quad$ Reactor coolant system

RPV: $\quad$ Reactor pressure vessel

RWT: Refueling water tank

SBLOCA: Small-break loss of coolant accident

SCS: $\quad$ Shutdown cooling system

SIP: $\quad$ Safety injection pump

SIS: $\quad$ Safety injection system

SMART: System-integrated modular advanced reactor (plant)

SMART-P: SMART-Pilot (plant)

SV: $\quad$ Separating vessel
TASS/SMR-S: Transient and set point simulation/small and medium reactor (computer code)

VISTA: $\quad$ Experimental verification by integral simulation of transients and accidents (facility)

VISTA-ITL: VISTA integral test loop (facility).

\section{Conflict of Interests}

The authors declare that there is no conflict of interests regarding the publication of this paper.

\section{Acknowledgments}

This work was supported by the National Research Foundation of Korea (NRF) Grant funded by the Korea government (MSIP) (no. 2013M2B9A1020039). Also the authors would like to thank Dr. Y. J. Chung, Dr. W. J. Lee (KAERI), Mr. D. H. Kang, and Dr. J. S. Suh (SEnTech, Co.) for their support and discussion during the pretest analysis by using the MARS-KS code.

\section{References}

[1] S. J. Yi, H. S. Park, K. Y. Choi et al., "Basic design of the high temperature/high pressure thermal-hydraulic test facility," KAERI Internal Report, KAERI, 2001.

[2] K. K. Kim, W. Lee, S. Choi et al., "SMART: the first licensed advanced integral reactor," Journal of Energy and Power Engineering, vol. 8, pp. 94-102, 2014.

[3] Y. J. Chung, K.S. Hyoung, K. S. Darl et al., “TASS/SMR code topical report for SMART plant, Vol. I: code structure, system models, and solution methods," KAERI/TR-3640/2008, 2008.

[4] B. D. Chung, S. W. Bae, J. J. Jeong et al., "Development and assessment of multi-dimensional flow models in the thermalhydraulic system analysis code MARS," KAERI/TR-3011/2005, 2005.

[5] Y.-G. Lee, I.-W. Park, and G.-C. Park, "SBLOCA and LOFW experiments in a scaled-down IET facility of rex-10 reactor," Nuclear Engineering and Technology, vol. 45, no. 3, pp. 347-360, 2013.

[6] Y.-G. Lee and G.-C. Park, "TAPINS: a thermal-hydraulic system code for transient analysis of a fully-passive integral PWR," Nuclear Engineering and Technology, vol. 45, no. 4, pp. 439-458, 2013.

[7] S. J. Yi, H. S. Park, T. S. Kwon et al., "Major results of thermalhydraulic validation tests for the SMART design licensing," in Proceedings of the 15th International Topical Meeting on Nuclear Reactor Thermal Hydraulics (NURETH '13), Pisa, Italy, May2013.

[8] K. Y. Choi, H. S. Park, H.S. Cho et al., "Parametric studies on thermal hydraulic characteristics for transient operations of an integral type reactor," Nuclear Engineering and Technology, vol. 38, no. 2, pp. 185-194, 2006.

[9] H.-S. Park, K.-Y. Choi, S. Cho, S.-J. Yi, C.-K. Park, and M.K. Chung, "Experiments on the performance sensitivity of the passive residual heat removal system of an advanced integral type reactor," Nuclear Engineering and Technology, vol. 41, no. 1, pp. 53-62, 2009. 
[10] W.-P. Baek, C.-H. Song, B.-J. Yun, T.-S. Kwon, S.-K. Moon, and S.-J. Lee, "Kaeri integral effect test program and the ATLAS design," Nuclear Technology, vol. 152, no. 2, pp. 183-195, 2005.

[11] M. Ishii and I. Kataoka, "Similarity analysis and scaling criteria for LWRs under single-phase and two-phase natural circulation," NUREG/CR-3267, ANL-83-32, 1983.

[12] H. S. Park, S. J. Yi, C. H. Song et al., "SMR accident simulation in experimental test loop," Nuclear Engineering International, pp. $12-15,2013$. 


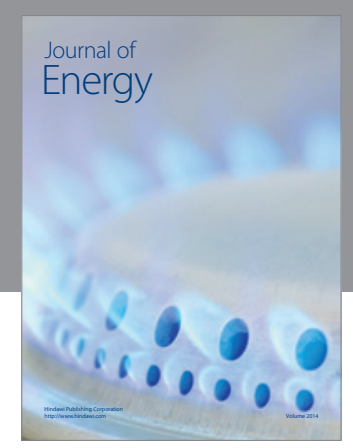

Journal of

Industrial Engineering
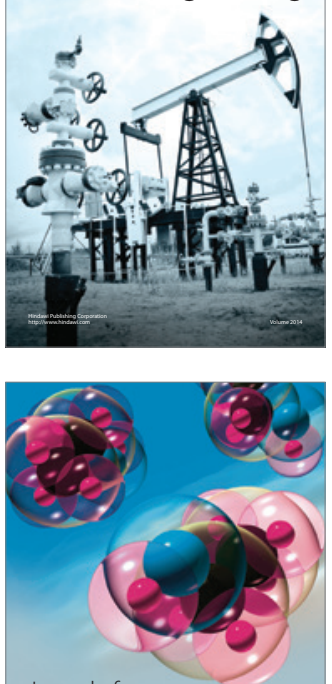

Fuels
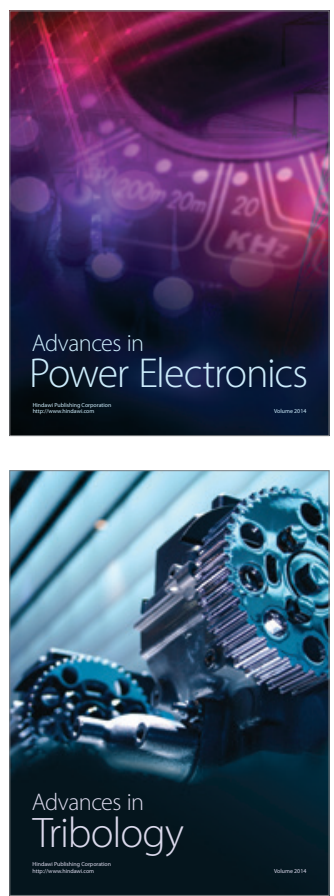

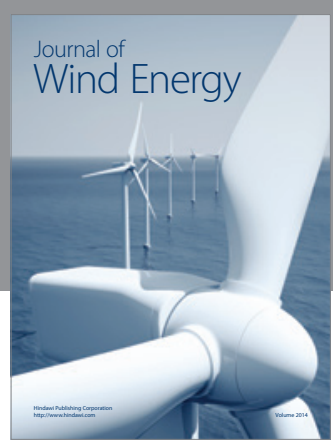

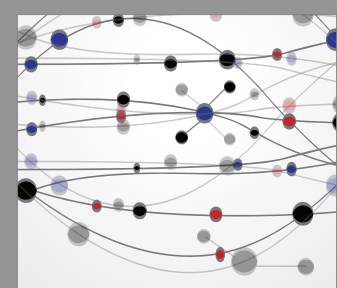

The Scientific World Journal

Submit your manuscripts at http://www.hindawi.com

Journal of

Structures
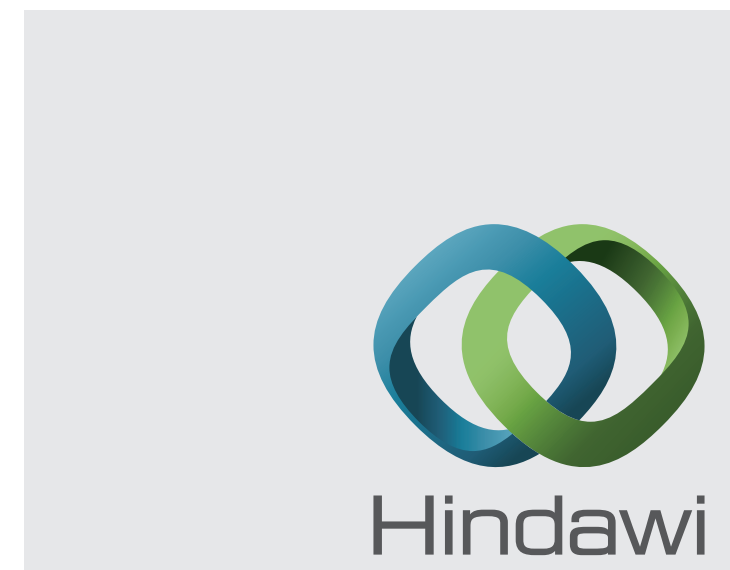

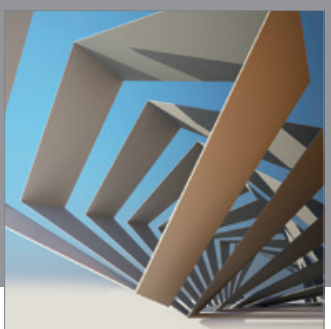

Rotating

Machinery
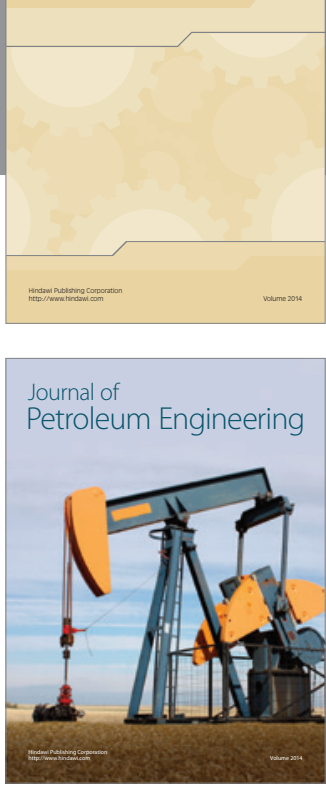

Journal of

Solar Energy
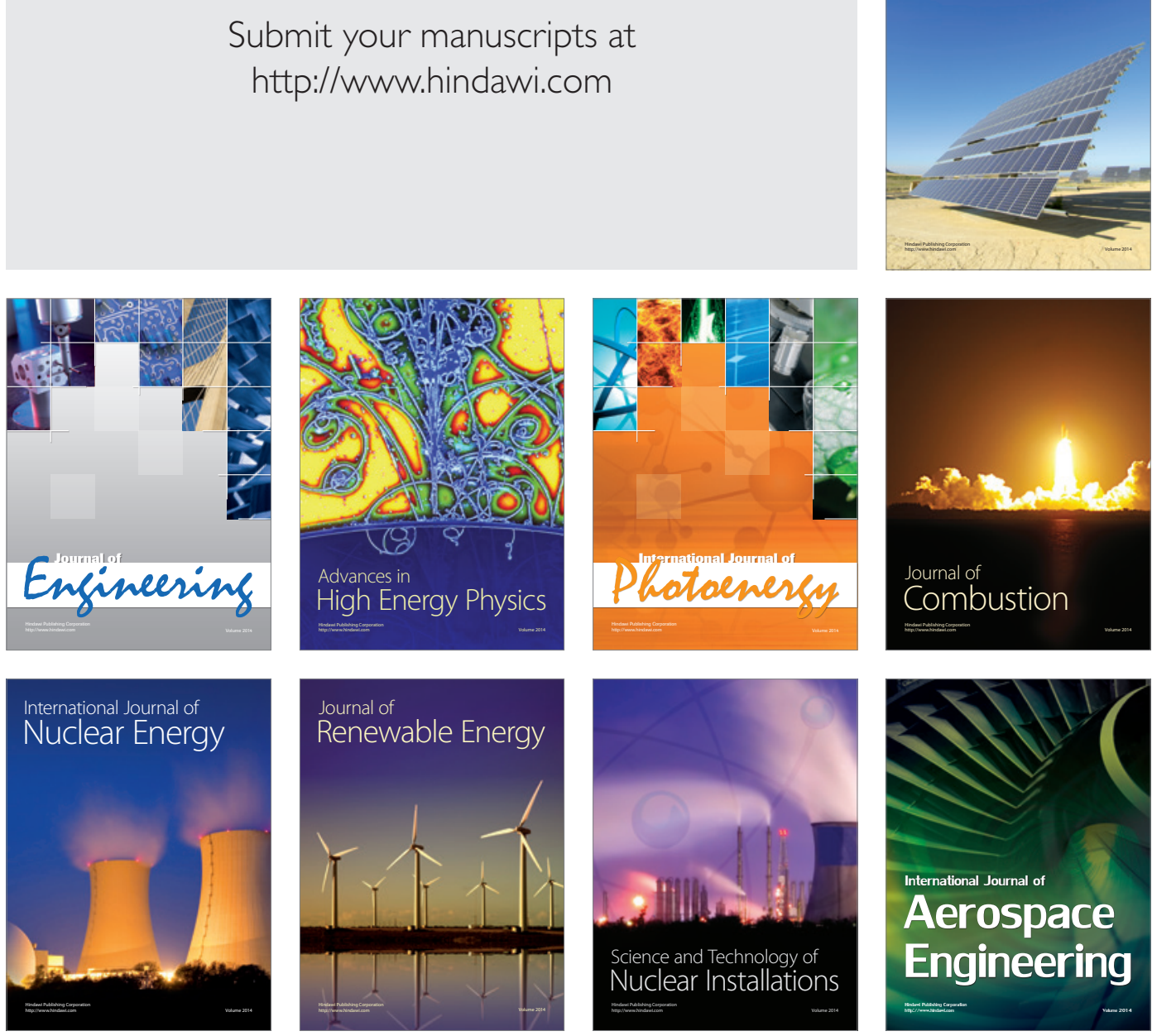